\title{
A SURVEY ON MULTILEVEL INVERTER TOPOLOGIES AND CONTROL SCHEMES WITH HARMONIC ELIMINATION
}

\section{CHITHRA M}

Assistant Professor, Department of EEE, CMR Institute of Technology, Bengaluru, Karnataka, India

\begin{abstract}
Multi level inverters have developed as an essential converter in high power medium voltage converters and it has tremendous contribution in renewable energy field. In an attempt to report the recent advances and trends in power electronics technology, this paper presents a review of various multi level converters which are extensively used in industrial applications. The paper focuses to summarize the technological advancements in neutral clamped, cascaded $H$ bridge topologies and flying capacitor. The paper also summarizes about various modulation techniques like fundamental modulation, carrier based PWM techniques, selective harmonic elimination technique etc.

KEYWORDS: multi level inverters, modulation schemes, pulse width modulation, total harmonic distortion (THD)
\end{abstract}

Received: May 03, 2020; Accepted: May 23, 2020; Published: Jun 26, 2020; Paper Id.: IJMPERDJUN2020105

\section{INTRODUCTION}

Over the recent years, voltage source converters and current source converters operating as rectifier or inverter have become intensive research interest and attracted many industrial application [1]. Inverter is a power semi-conductor device which is used to convert fixed DC signal into variable voltage variable frequency AC signal [2] [3].

Among the voltage source inverters, multilevel converters have arrived as a critical converter in high power applications [4]. The term multilevel denotes converter which is capable of providing two or more levels of voltage. By increasing amount of voltage level, the output voltage with additional steps can generate a staircase waveform which leads to approximated sine waveform with reduced harmonic contents. MLIs require separate DC sources which enables the use of renewable energy sources like photo voltaic(PV) cell, fuel cells, bio cells etc.,[5][6]

Among the various multilevel configurations, the most preferred ones are Flying Capacitor/Capacitor clamped, Cascaded H Bridge (CHB), and Neutral clamped. Compared to conventional two level square wave inverters, MLIs generate a sine wave with requirement of less no of filters [4].Multilevel inverters don't require transformers which eliminates magnetic interference problems. Among various multilevel inverter topologies, modular multilevel converter (MMC) plays as a game changer in various industrial applications and solutions [7]

\section{Multilevel Inverter Topologies}

MLIs have attracted numerous applications in recent decades due to increased power rating, reduced voltage stress, reduced total harmonic distortion and reduced electro-magnetic interference. Depending on the type of source used these inverters are classified as VSI (Voltage Source Inverter) or CSI (current source inverter) [8] [9]. 


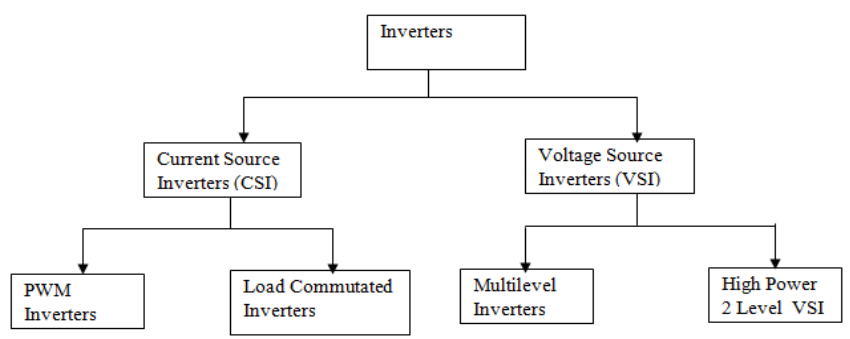

Figure 1: Classification of Inverters.

Plenty of MLI topologies have been introduced during the last two decades. This article briefly discusses about various multilevel inverter topologies and harmonic elimination techniques which has attracted many industrial applications and found in literatures like neutral clamped, capacitor clamped, cascaded connected $\mathrm{H}$ bridge with split dc sources, modulated multilevel converter and asymmetric hybrid converters [10].

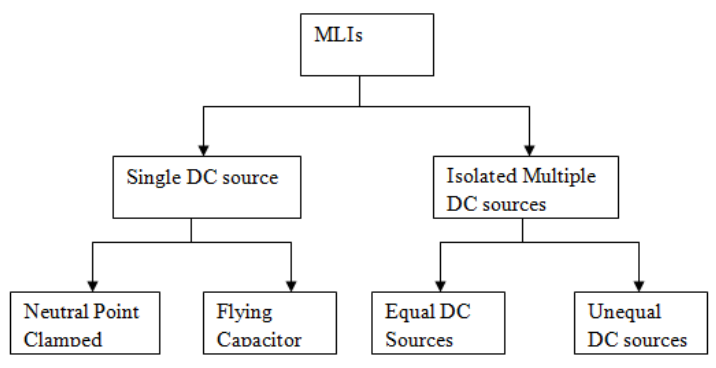

Figure 2: Multi Level Inverters- Classification.

\section{Diode Clamped Multilevel Inverters}

This is one of the important multi-level inverter topologies which are also known as neutral point clamped NPC inverter which utilizes series connected diodes along with capacitors to divide the input side voltage into numerous stages. For $n$ stage MLI, $(n-1)$ DC sources and $(n-1)$ diodes are required. [11][12]. An example of five-stage neutral clamp multilevel inverter is shown in fig 3.

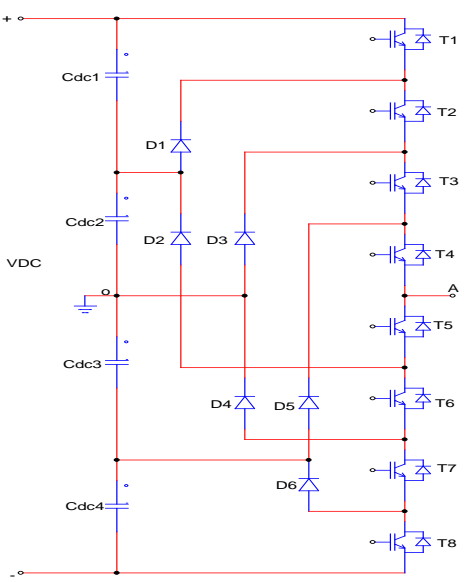

Figure 3: Diode Clamped Inverter - Five

Level. 
Table 1: Five Stage-Diode Clamp Inverter - Switching States

\begin{tabular}{|c|c|c|c|c|c|c|c|c|}
\hline T1 & T2 & T3 & T4 & T5 & T6 & T7 & $\mathrm{T} 8$ & Vout \\
\hline 1 & 1 & 1 & 1 & 0 & 0 & 0 & 0 & $\mathrm{~V}_{\text {IN }} / 2$ \\
\hline 0 & 1 & 1 & 1 & 1 & 0 & 0 & 0 & $\mathrm{~V}_{\text {IN }} / 4$ \\
\hline 0 & 0 & 1 & 1 & 1 & 1 & 0 & 0 & 0 \\
\hline 0 & 0 & 0 & 1 & 1 & 1 & 1 & 0 & $-\mathrm{V}_{\text {IN }} / 4$ \\
\hline 0 & 0 & 0 & 0 & 1 & 1 & 1 & 1 & $-\mathrm{V}_{\text {IN }} / 2$ \\
\hline
\end{tabular}

If the input voltage is $\mathrm{V}_{\mathrm{IN}}$, the voltage across every capacitor is one fourth of the input voltage thus all the switching device voltage stress is reduced to one fourth due to the use of diodes [13].

\section{Flying Capacitor/ Capacitor Clamped Multilevel Inverter - Fcmli}

FCMLI topology is almost identical to diode/neutral clamped MLIs, except the factor that clamping capacitors are utilized in its place of clamp diodes to clamp voltage. [14][15]. An example of five level FCMLI and its switching levels are shown in table 2 and figure 4

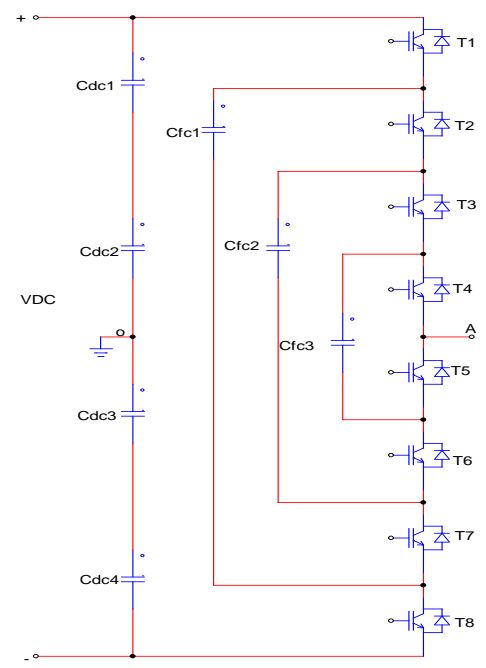

Figure 4: Flying Capacitor Multilevel Inverter - Five Levels.

Table 2: Five Level Flying Capacitor Topology Switching States

\begin{tabular}{|c|c|c|c|c|c|c|c|c|}
\hline T1 & T2 & T3 & T4 & T5 & T6 & T7 & T8 & Vout \\
\hline 1 & 1 & 1 & 1 & 0 & 0 & 0 & 0 & $\mathrm{~V}_{\text {IN }} / 2$ \\
\hline 0 & 1 & 1 & 1 & 1 & 0 & 0 & 0 & $\mathrm{~V}_{\text {IN }} / 4$ \\
\hline 0 & 0 & 1 & 1 & 1 & 1 & 0 & 0 & 0 \\
\hline 0 & 0 & 0 & 1 & 1 & 1 & 1 & 0 & $-\mathrm{V}_{\text {IN }} / 4$ \\
\hline 0 & 0 & 0 & 0 & 1 & 1 & 1 & 1 & $-\mathrm{V}_{\text {IN }} / 2$ \\
\hline
\end{tabular}

The primary advantage of FCMLI topology is that it allows switching redundancies i.e. two are more switching combinations can yield the particular voltage level which is not feasible in case of neutral/ diode clamped inverter. [16] The auxiliary diodes are precharged to required voltage levels which ensure the usefulness of the converter to allow it to generate multi step waveforms. The major advantages of FCMLI are it reduces the requirement of filter and also controls real and reactive power flow in addition to phase redundancies. But with increasing voltage levels, the charging and discharging of the capacitors are not accurate and also leads to increase in cost due to increased number of levels.[17][18] 


\section{Cascaded H Bridge Multilevel Inverters CHBMLIS}

Among available various MLI topologies, the CHBMLIs provide a promising alternative with modular design which enables transformer less connections. The idea of $\mathrm{H}$ bridge MLI is derived from connecting full CHBMLI in succession to obtain a sinusoidal voltage quantity. [19][20] The resultant output is the summation of voltages contributed by individual $\mathrm{H}$ Bridge. By properly selecting the switching states, each $\mathrm{CHB}$ inverter would generate three voltage levels i.e. positive $+\mathrm{V}$, negative $-\mathrm{V}$ and zero -0 level. The number of cells / $\mathrm{H}$ bridges required depends on operating voltage and manufacturing cost [14]. In any CHB MLI, if $2 n+1$ is the desired output voltage level then $n$ would be the number of separate cells required. The CHB multilevel inverters might use equal or unequal dc sources accordingly; there exist symmetrical or asymmetrical CHB MLI topologies.

The basic structure of five level symmetrical CHB MLI topology and switching possibilities are shown in the figure 5 and table 3.

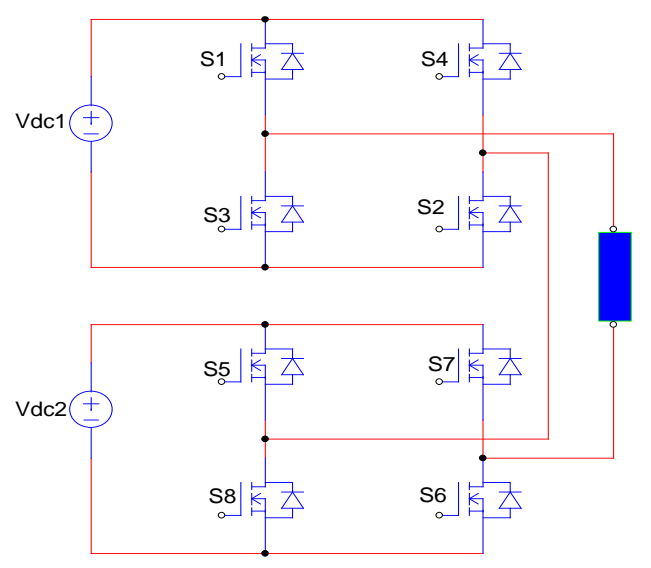

Figure 5: Symmetrical Chb Mli - Five Stage.

Table 3: Five Level CHB Topology Switching States

\begin{tabular}{|c|c|c|c|c|c|c|c|c|}
\hline S1 & S2 & S3 & S4 & S5 & S6 & S7 & S8 & Output voltage \\
\hline 1 & 1 & 0 & 0 & 1 & 1 & 0 & 0 & $\mathrm{~V}_{\text {IN }} / 2$ \\
\hline 1 & 1 & 0 & 0 & 1 & 0 & 1 & 0 & $\mathrm{~V}_{\text {IN }} / 4$ \\
\hline 0 & 1 & 1 & 0 & 1 & 0 & 1 & 0 & 0 \\
\hline 0 & 1 & 1 & 0 & 0 & 0 & 1 & 1 & $-\mathrm{V}_{\text {IN }} / 4$ \\
\hline 0 & 0 & 1 & 1 & 0 & 0 & 1 & 1 & $-\mathrm{V}_{\text {IN }} / 2$ \\
\hline
\end{tabular}

Apart from providing redundancies in switching states, the CHB MLIs require lesser amount of switching elements compared to capacitor clamped or diode clamped topologies which results in less manufacturing cost and weight of the converter[21].Moreover CHB MLIs are available with higher voltages(13.8kV) and power levels (30MVA) which attracts many researchers and industrial collaborators.[22]

\section{Emerging Multilevel Inverter Topologies}

Apart from the existing topologies, there are several hybrid configurations which are finding wide applications in voltage control. Few of the upcoming topologies are mentioned below. 


\section{Hybrid Multilevel Cells}

Instead of cascaded $\mathrm{H}$ bridge inverters, it is feasible to have cascaded multilevel capacitor clamped or neutral point clamped inverters in various applications. Such combinations of above mentioned conventional multilevel inverter topologies leads to hybrid multi-level inverters. These proposed multilevel inverters mainly aims at reducing the number of separate DC sources required [23] [24].

One such hybrid nine level mixed multilevel inverter using capacitor clamped is shown below.

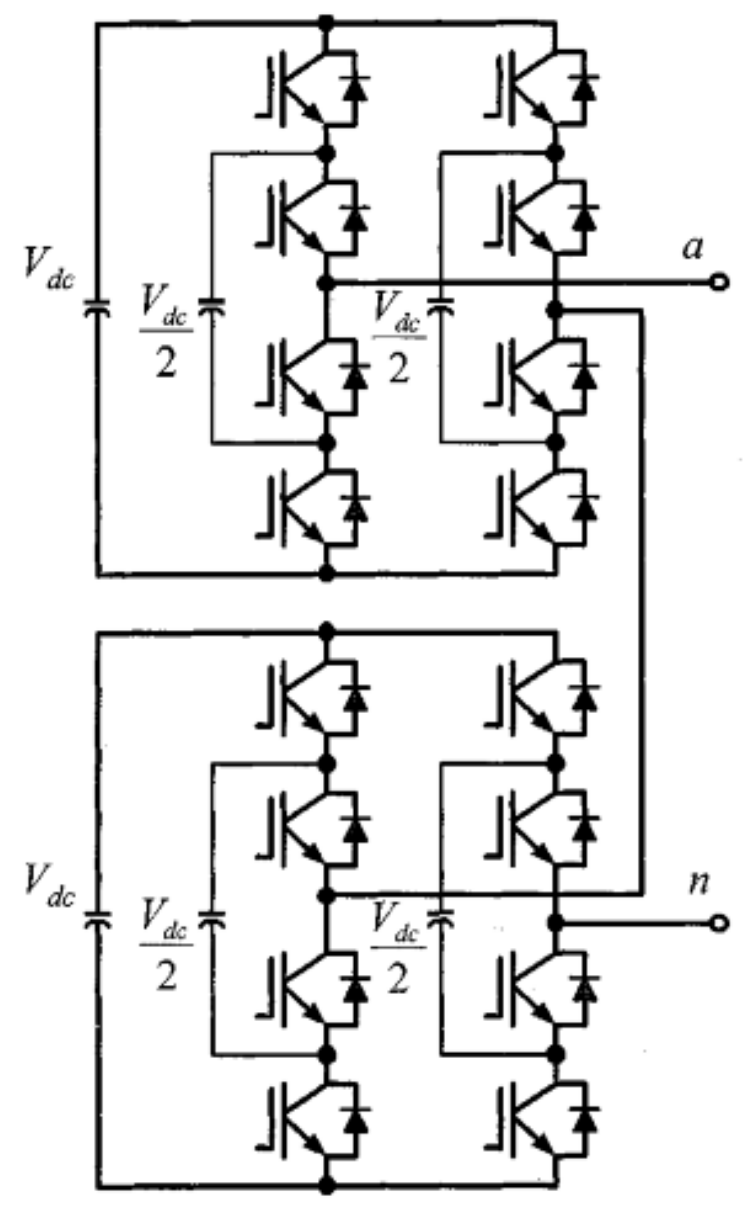

Figure 6: Nine Level Hybrid Cell Configuration using Clamping Capacitor to Increase Voltage Level.

\section{Asymmetric Hybrid Multilevel Cells}

In most of the CHB multi level inverter configurations, the separate DC sources used will be of equal magnitude. However it is possible to have different voltage sources and such a converter is called as asymmetric multilevel converter. The primary objective of this asymmetric inverter topology is to use less number of semi-conductor switches compared with symmetrical configuration with an interesting feature of achieving higher voltage level with same number of cells i.e., in case of symmetrical topology the number of level increases proportionately to the number of cells whereas herein asymmetrical topology it becomes exponentially. [25][26]

\section{Soft Switched Multi Inverters}

Soft switching schemes are becoming popular due to reduced switching losses and increased efficiency. With conventional 
hard switching inverters electromagnetic interference is a major problem. Even though zero current switching is feasible utmost the literature proposes zero voltage switching topology for multilevel inverter voltage control. [27]

\section{Three Phase Hybrid Inverters:[28]}

Several three phase hybrid inverters are now a days proposed by various researchers. One such example of hybrid inverter suitable for three phase loads with reduced switching components in comparison with traditional three phase cascaded $\mathrm{H}$ bridge topology is shown in the figure

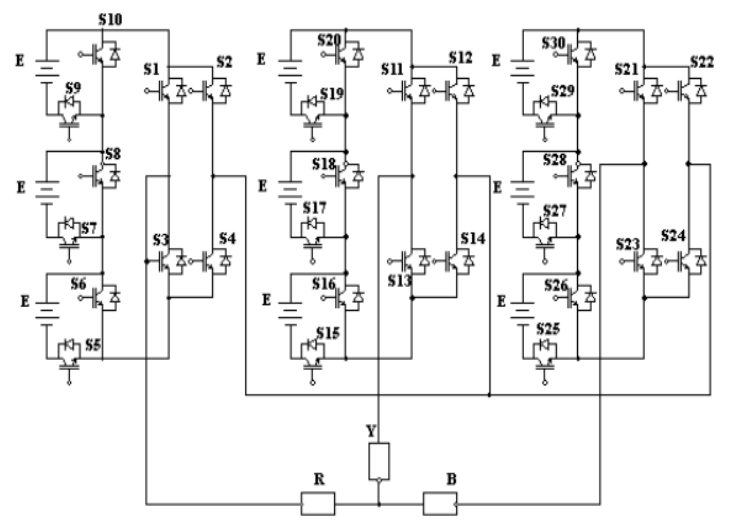

Figure 7: Hybrid three phase DC link Multi Level Inverter.

In conventional topology. 36 switches are required whereas this proposed hybrid topology uses fewer switches i.e. for $m$ level output voltage $m+3$ switches per phase is only required. For this topology, the preferred modulation techniques are sub harmonic and SVPWM methods. The per phase switching states for hybrid inverter is shown in the table 4.

Table 4: Per Phase Switching States Hybrid CHB Inverter

\begin{tabular}{|c|c|c|c|c|c|c|c|c|c|c|}
\hline Vo & S1 & S2 & S3 & S4 & S5 & S6 & S7 & S8 & S9 & S10 \\
\hline 0 & 1 & 0 & 0 & 1 & 0 & 1 & 0 & 1 & 0 & 1 \\
\hline E & 1 & 0 & 0 & 1 & 0 & 1 & 0 & 1 & 1 & 0 \\
\hline 2E & 1 & 0 & 0 & 1 & 0 & 1 & 1 & 0 & 1 & 0 \\
\hline $3 \mathrm{E}$ & 1 & 0 & 0 & 1 & 1 & 0 & 1 & 0 & 1 & 0 \\
\hline$-\mathrm{E}$ & 0 & 1 & 1 & 0 & 0 & 1 & 0 & 1 & 1 & 0 \\
\hline$-2 \mathrm{E}$ & 0 & 1 & 1 & 0 & 0 & 1 & 1 & 0 & 1 & 0 \\
\hline$-3 \mathrm{E}$ & 0 & 1 & 1 & 0 & 1 & 0 & 1 & 0 & 1 & 0 \\
\hline
\end{tabular}

\section{Control and Modulation Approach}

\section{Overview \& Classification - Modulation Approaches}

The choice of modulation strategy for MLI is an essential issue for any multilevel inverter control. The modulation approaches are classified as fundamental and high frequency methods based on switching frequency used for pulse generation[29].The fundamental switching frequency technique which is also called as low switching frequency requires less commutations of switches for one cycle-operation. SHE (selective harmonic elimination) technique and SVM (space vector modulation) technique are examples of low switching frequency. High switching frequency modulation technique requires many commutations of power switches during one cycle of the output voltage. Carrier based PWM technique is the most preferred switching technique among the high switching frequency methods, which needs phase shifting technique so that harmonic components are reduced in load voltage [30]. 


\section{Selective Harmonic Elimination Modulation Technique}

In low frequency switching modulation techniques, all the power switches are turned on and off only once per fundamental cycle, therefore compared to carrier based PWM techniques switching losses are less. The drawback of fundamental switching frequency is that the range of modulation index is narrow which leads to increase in total harmonic distortion THD [31],[32].SHE can be utilized at low switching frequencies without compromise on quality of power and it is also one of the most preferred modulation techniques for medium and high power applications. As the side band frequency near the carrier frequency produces lower order harmonics distortions, techniques like carrier based pulse width modulation should not be used for applications which requires low switching frequencies. [33]

Cascaded $\mathrm{H}$ bridge inverter used to produce 7 output voltage level taken as case study [34] is shown in the figure

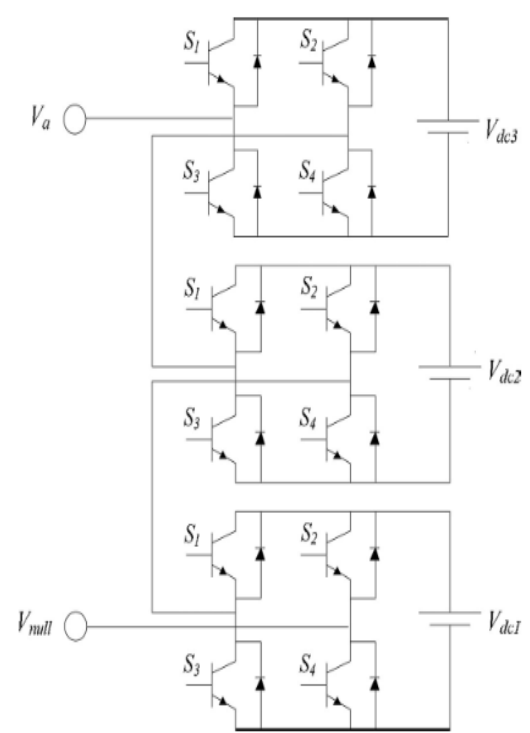

Figure 8: Cascaded H Bridge Mli -

Seven Level.

The voltage derived using Fourier analysis is given below,

$V(\mathrm{wt})=\sum_{n=1}^{\infty} V n \sin n w t$

In the above equation, $\mathrm{Vn}$ represents the amplitude of nth harmonic component.

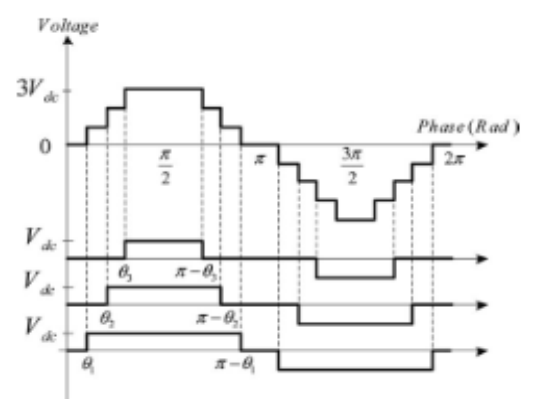

Figure 9: Output Voltage Waveform 7 Level CHB MLI. 
Even order harmonics are zero, since the waveform has odd quarter symmetric,

Consequently Vn becomes [35],

$V n=\frac{4 V d c}{n \Pi} \sum_{i=1}^{s} \cos n \theta i$ for odd $\mathrm{n}$

$=0$ for even $\mathrm{n}$

To eliminate fifth and seventh order harmonics, the non linear equations can be written as,

$\mathrm{V}_{1}=\frac{4 \mathrm{Vdc}}{\pi}\left[\cos \theta_{1}+\cos \theta_{2}+\cos \theta_{3}\right]$

$\mathrm{V}_{5}=\frac{4 \mathrm{Vdc}}{5 \pi}\left[\cos 5 \theta_{1}+\cos 5 \theta_{2}+\cos 5 \theta_{3}\right] \ldots \ldots$.

$\mathrm{V}_{7}=\frac{4 \mathrm{Vdc}}{7 \pi}\left[\cos 7 \theta_{1}+\cos 7 \theta_{2}+\cos 7 \theta_{3}\right]$

To eliminate $5^{\text {th }}$ and $7^{\text {th }}$ order harmonics $V_{5}$ and $V_{7}$ should be set to according to the modulation index range given below,

$$
\mathrm{M} \cong \frac{V_{1}}{12 V d c / \pi} \ldots \ldots
$$

Using (3) and (4), the equations can be simplified as follows,

$$
\begin{aligned}
& M=\frac{1}{3}\left[\cos \theta_{1}+\cos \theta_{2}+\cos \theta_{3}\right] \\
& 0=\cos 5 \theta_{1}+\cos 5 \theta_{2}+\cos 5 \theta_{3} \\
& 0=\cos 7 \theta_{1}+\cos 7 \theta_{2}+\cos 7 \theta_{3}
\end{aligned}
$$

The above equations can be simplified using iterative methods like Newton- Rapson to find the angles $\theta_{1}, \theta_{2} \& \theta_{3}$ corresponding the range of $\mathrm{M}$.

The drawback of SHE is that for different levels different switching angles should be calculated according to chosen $\mathrm{M}$ which involves tedious calculations [36]. The major challenge with the technique is to find the detailed solutions of equations that contain complicated terms like trigonometric terms which might provide different set of solutions.[37],[38] [39]

\section{Multicarrier PWM Techniques}

There exist several PWM techniques for multi-level inverters [40] which can be generalized into two categories as mentioned below,

- Single carrier sinusoidal PWM

- Sub harmonic or level shifted PWM 
The sub harmonic or level shifted PWM is widely used modulation strategy [41] [42] which can be further classified as shown below in the figure 10

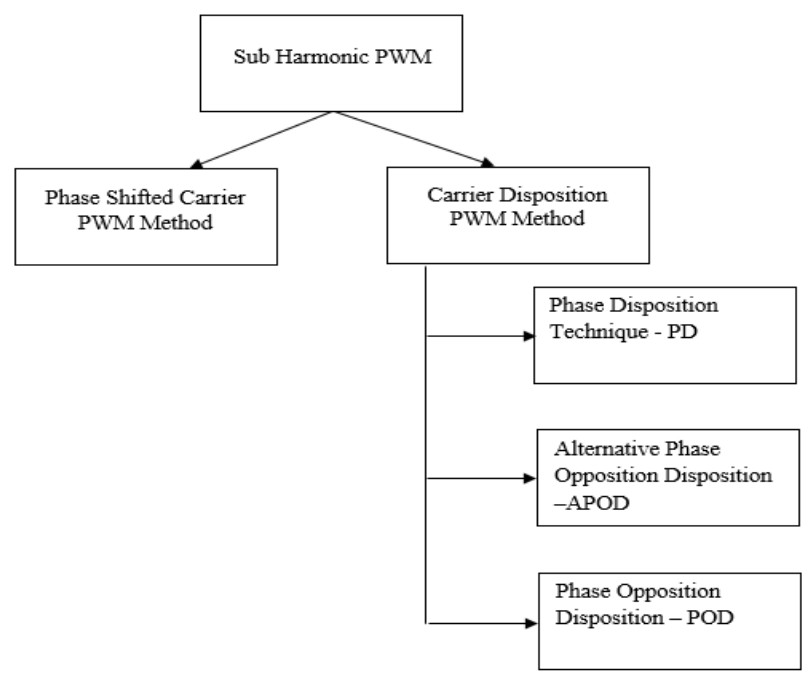

Figure 10: Classification of Level Shifted PWM.

In order to evaluate and describe different PWM modulation techniques, the following definitions are useful.

Frequency modulation index $\mathrm{m}_{\mathrm{f}}=\frac{\mathrm{f}_{\mathrm{cr}}}{\mathrm{f}_{\mathrm{m}}}$,

where

$f_{c r}$ represents carrier signal frequency

and $f_{m}$ represents reference signal frequency.

Amplitude modulation index $\mathrm{m}_{\mathrm{a}}=\frac{\mathrm{v}_{\mathrm{m}}}{\mathrm{v}_{\mathrm{cr}}(\mathrm{m}-1)}$, where $v_{m}$ represents peak amplitude of modulating wave and $v_{c r}$ represents peak amplitude of carrier wave.

Displacement angle $\Phi$, the angle of displacement between reference sine signal and the first appearing positive carrier signal.

\section{Single Carrier SPWM}

Reference sinusoidal voltage waveform is compared with carrier triangular waveform in order to generate gate pulse signals for the switches of the inverter in this technique [43] [44]. The carrier signal is a triangular waveform with frequency fc and amplitude Ac. The reference signal is a sine waveform with frequency fm and amplitude Am. The modulation index is given by

$$
m_{i}=\frac{A_{m}}{M A_{c}}
$$

Where 
$\mathrm{M}$ represents - number of required converter cells

i.e. $\mathrm{M}=3$ for seven level converter

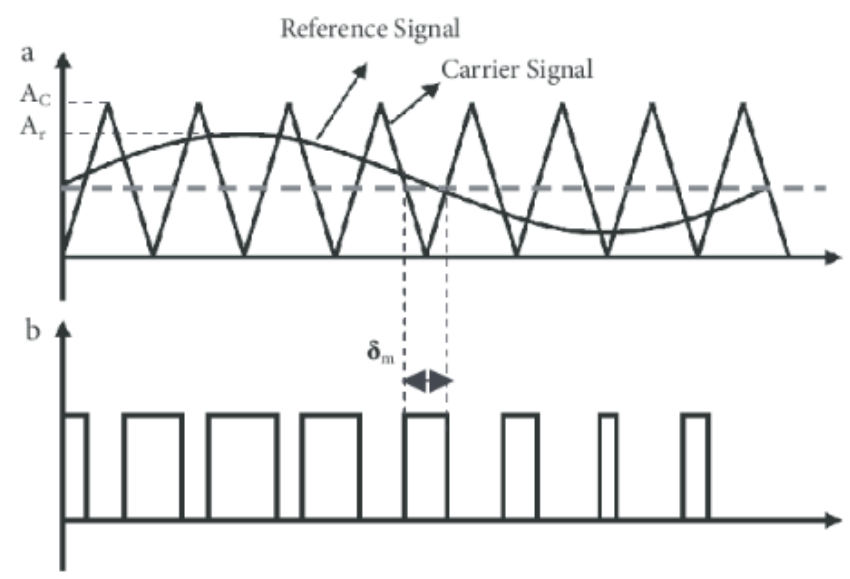

Figure 11: Single Carrier Sinusoidal PWM.

\section{Phase Shifted Carrier PWM Method PSCPWM}

The phase shifted carrier PWM [45] [46] technique is the commonly used modulation strategy for cascaded H Bridge MLIs. The major advantages of PSC PWM are equal switch and power utilization. There exist phase differences between each carrier signals which can be calculated by the given equation (6), in which $\mathrm{m}$ is the number of level in cascaded $\mathrm{H}$ bridge topology. Hence if there are seven levels, the six carrier signals require $60^{\circ}$ phase difference between each.

$$
\phi_{c r}=\frac{360}{m-1}
$$

\section{Carrier Disposition or Level Shifted PWM}

In carrier disposition method, the various carrier signals are placed at different levels with respect to each other and reference signal. The most widely used level shifted PWM techniques [47] [48] [49] are

- Phase Disposition PWM (PDPWM)

- Phase Opposition Disposition (POD PWM)

- Alternate Phase Opposition Disposition (APOD PWM)

\section{PDPWM}

In phase disposition method, all carrier signals are in- phase. For i level inverter, (i-1) identical triangular carrier signals are placed one upon the other and compared with modulating signal. The frequency of the carrier signal is calculated by

$$
f_{c}=3 *(2 \mathrm{k}+1) \mathrm{f}_{\mathrm{m}}
$$

Where $\mathrm{k}$ is a positive integer and $\mathrm{f}_{\mathrm{m}}$ is the frequency of the modulating signal. Compared to other carrier disposition methods, it is found that this method gives rise to lower order harmonics with higher modulation indices.The arrangement of carrier signals and reference signal for a seven level cascaded H bridge inverter [50] is shown in fig 12 


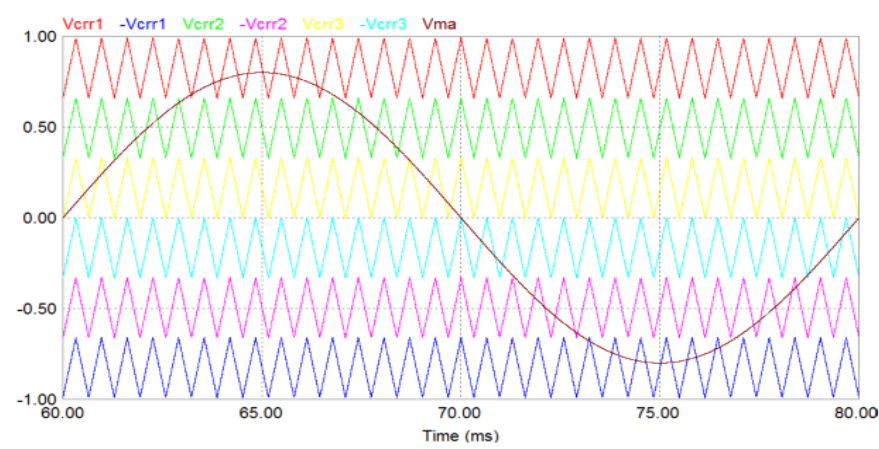

Figure 12: Carrier and Modulating Waveforms PD PWM - 7 Level CHB MLI.

\section{POD PWM}

In phase opposition disposition technique, [51]the carrier signals above the sinusoidal reference zero point are 180 ${ }^{\circ}$ out of phase with those below the zero point.i.e. the carrier signals above the zero reference line are in phase and below are also in phase but are 180 phase shifted from those above zero as shown in fig 13. [52][53]Compared to PD PWM method, the harmonic performance is better.

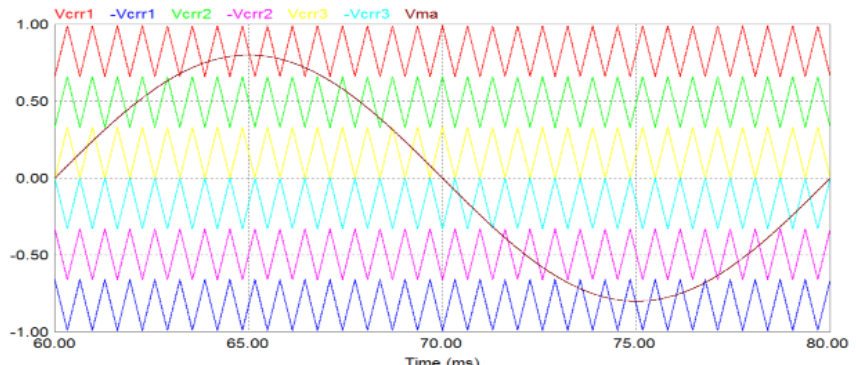

Figure 13: Carrier and Modulating Waveforms PODPWM - 7 Level CHB MLI.

\section{APOD PWM}

In this modulation technique, which is believed to have better harmonic spectrum has [54] each carrier signal phase shifted by 180 from its adjacent one. The comparison of carrier and modulating signals is shown in fig 14 .

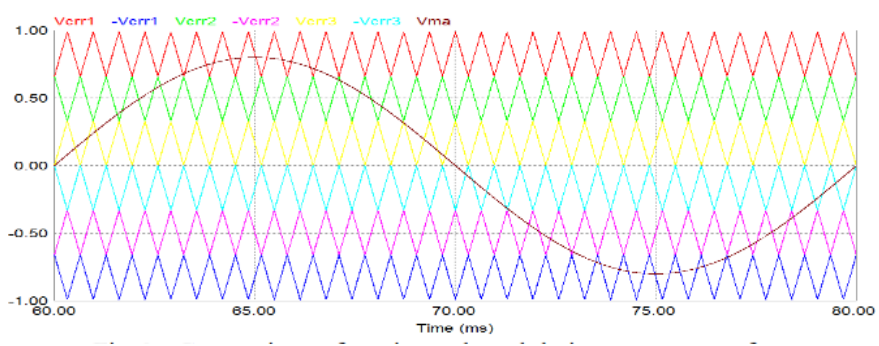

Figure 14: Carrier and Modulating Waveforms APOD PWM - 7 Level CHB MLI.

The harmonic performance of CHB MLI from 3 to 9 levels using various phase shifted PWM techniques has been summarized in the table 5 [55] [56] [57] 
Table 5: Comparison of Thd using Different PWM Techniques

\begin{tabular}{|c|c|c|c|}
\hline S NO & Number of Levels & PWM Technique & THD \% \\
\hline 1 & \multirow{3}{*}{3 level } & PD & 52.06 \\
\hline 2 & & POD & 54.17 \\
\hline 3 & & A-POD & 54.17 \\
\hline 4 & \multirow{3}{*}{5 level } & PD & 26.69 \\
\hline 5 & & POD & 26.96 \\
\hline 6 & & A-POD & 37.13 \\
\hline 7 & \multirow{3}{*}{7 level } & PD & 18.05 \\
\hline 8 & & POD & 22.48 \\
\hline 9 & & A-POD & 25.20 \\
\hline 10 & \multirow{3}{*}{9 level } & $\mathrm{PD}$ & 16.77 \\
\hline 11 & & POD & 17.08 \\
\hline 12 & & A-POD & 17.10 \\
\hline
\end{tabular}

From the table [58] it can be concluded that with increasing levels the harmonics are getting reduced

\section{CONCLUSIONS}

This paper has analyzed different multilevel inverter topologies and control strategies suited for engineering applications. From the literature it is concluded that with increasing number of levels, the harmonic content THD gets reduced but requires more switching devices which results in increased cost and switching losses. So the designer is in a need to have tradeoff between voltage level and number of switching devices required. The conventional topologies which serve as the basis of several hybrids modern converters are given emphasis. The paper also reviewed emerging hybrid topologies with reduced switching devices including three phase topology. Compared to traditional topologies, the above mentioned hybrid topologies appear to have low total harmonic distortion and also requires less number of power semi-conductor components. It is strongly believed that this review article might serve as a source of literature for various new upcoming researchers in the multilevel voltage source inverter field.

\section{REFERENCES}

1. Dahidah, Mohamed SA, and Vassilios G. Agelidis. "Selective harmonic elimination PWM control for cascaded multilevel voltage source converters: A generalized formula." IEEE Transactions on power electronics 23.4 (2008): 1620-1630.

2. Rodriguez, Jose, Jih-Sheng Lai, and Fang Zheng Peng. "Multilevel inverters: a survey of topologies, controls, and applications." IEEE Transactions on industrial electronics 49.4 (2002): 724-738.

3. Colak, Ilhami, Ersan Kabalci, and Ramazan Bayindir. "Review of multilevel voltage source inverter topologies and control schemes." Energy conversion and management 52.2 (2011): 1114-1128.

4. Rodríguez, José, et al. "Multilevel voltage-source-converter topologies for industrial medium-voltage drives. "IEEE Transactions on industrial electronics 54.6 (2007): 2930-2945.

5. Huang, Soudan, et al. "Space vector PWM techniques for current and voltage source converters: A short review." 2012 15th International Conference on Electrical Machines and Systems (ICEMS). IEEE, 2012. 
6. Touati Mohamed, Shaoyuan Li, and Jing Wu. "Multi-level model predictive controller with satisfactory optimization for multi-level converters. "Simulation Modelling Practice and Theory 92 (2019): 1-16.

7. Duarte, Samuel N., Pedro M. de Almeida, and Pedro G. Barbosa. "A novel energizing strategy for a grid-connected modular multilevel converter operating as static synchronous compensator." International Journal of Electrical Power \& Energy Systems 109 (2019): 672-684.

8. Chiasson, John, et al. "Eliminating harmonics in a multilevel converter using resultant theory." 2002 IEEE 33 rd Annual IEEE Power Electronics Specialists Conference. Proceedings (Cat. No. 02CH37289). Vol. 2. IEEE, 2002.

9. Chiasson, John N., et al. "Elimination of harmonics in a multilevel converter using the theory of symmetric polynomials and resultants." IEEE Transactions on Control Systems Technology 13.2 (2005): 216-223.

10. Koshti, Amol K., and M. N. Rao. "A brief review on multilevel inverter topologies." 2017 International Conference on Data Management, Analytics and Innovation (ICDMAI). IEEE, 2017.

11. Krishna, R. Anjali, and L. Padma Suresh. "A brief review on multi level inverter topologies." 2016 International Conference on Circuit, Power and Computing Technologies (ICCPCT). IEEE, 2016.

12. Shehu, Gaddafi Sani, et al. "A review of multilevel inverter topology and control techniques." (2016).

13. Colak, Ilhami, Ersan Kabalci, and Ramazan Bayindir. "Review of multilevel voltage source inverter topologies and control schemes." Energy conversion and management 52.2 (2011): 1114-1128.

14. Gupta, Krishna Kumar, et al. "Multilevel inverter topologies with reduced device count: A review." IEEE transactions on Power Electronics 31.1 (2015): 135-151.

15. Peng, Fang Z., Wei Qian, and Dong Cao. "Recent advances in multilevel converter/inverter topologies and applications." The 2010 International Power Electronics Conference-ECCE ASIA-. IEEE, 2010.

16. Samarth, Sajal S., and R. A. Keswani. "Diode Clamped Multilevel Inverter for Induction Motor Drive." (2018).

17. Malinowski, Mariusz, et al. "A survey on cascaded multilevel inverters." IEEE Transactions on industrial electronics 57.7 (2009): 2197-2206.

18. Mittal, Nupur, et al. "Multilevel inverters: A literature survey on topologies and control strategies." 20122 nd International Conference on Power, Control and Embedded Systems. IEEE, 2012.

19. Yuan, Xiaoming. "Soft switching techniques for multilevel inverters." (1998).

20. Boussada, Zina, Omessaad Elbeji, and Mouna Benhamed. "Different topologies and control techniques of multi level inverter: A literature survey." 2017 International Conference on Green Energy Conversion Systems (GECS). IEEE, 2017.

21. Babaei, Ebrahim, and Seyed Hossein Hosseini. "New cascaded multilevel inverter topology with minimum number of switches." Energy Conversion and Management 50.11 (2009): 2761-2767.

22. Mohamad, A. S., Mariun, N., Sulaiman, N., \& Radzi, M. A. M. (2014, May). A new cascaded multilevel inverter topology with minimum number of conducting switches. In 2014 IEEE Innovative Smart Grid Technologies-Asia (ISGT Asia) (pp. 164-169). IEEE. 
23. Rodriguez, Jose, Jih-Sheng Lai, and Fang Zheng Peng. "Multilevel inverters: a survey of topologies, controls, and applications." IEEE Transactions on industrial electronics 49.4 (2002): 724-738.

24. Tolbert, Leon M., and Thomas G. Habetler. "Novel multilevel inverter carrier-based PWM method." IEEE Transactions on industry applications 35.5 (1999): 1098-1107.

25. Lou, H., Mao, C., Wang, D., Lu, J., \& Wang, L. (2014). Fundamental modulation strategy with selective harmonic elimination for multilevel inverters. IET Power Electronics, 7(8), 2173-2181.

26. Kavousi, A., Vahidi, B., Salehi, R., Bakhshizadeh, M. K., Farokhnia, N., \& Fathi, S. H. (2011). Application of the bee algorithm for selective harmonic elimination strategy in multilevel inverters. IEEE Transactions on power electronics, 27(4), 1689-1696.

27. Gnanavel, C., Kamalamoorthy, N., \& Prabhu, V. (2013). Assessment among Single and ThreePhase 14-Echelon Cascaded Multilevel Inverter. International Journal of Scientific and Research Publications, 3(5).

28. Shanono, Ibrahim Haruna, Nor Rul Hasma Abdullah, and Aisha Muhammad. "A survey of multilevel voltage source inverter topologies, controls, and applications." International Journal of Power Electronics and Drive Systems 9.3 (2018): 1186.

29. Swaroop, Ram, and Mukesh Kumar Kuldeep. "Decrease Total Harmonics Distortion by using Filter in Three Phase 27-Level CMI." International Journal on Recent Technologies in Mechanical and Electrical Engineering 5.9 (2018): 08-10.

30. Mandekar, M. H., Patel, M. P., Udhwadkar, M. Y., Tandel, M. D., \& Pandav, M. P. (2019). A-5 Level Inverter for Regulated Power Supply from DC Generator. IJRAR-International Journal of Research and Analytical Reviews (IJRAR), 6(2), 92-94.

31. Dahidah, M. S., \& Agelidis, V. G. (2008). Selective harmonic elimination PWM control for cascaded multilevel voltage source converters: A generalized formula. IEEE Transactions on power electronics, 23(4), 1620-1630.

32. Manjrekar, M. D., \& Lipo, T. A. (1998, February). A hybrid multilevel inverter topology for drive applications. In Proc. APEC (Vol. 2, pp. 523-9).

33. Govindaraju, C., \& Baskaran, K. (2011). Efficient sequential switching hybrid-modulation techniques for cascaded multilevel inverters. IEEE Transactions on Power Electronics, 26(6), 1639-1648.

34. Wu, F., Duan, J., \& Feng, F. (2015). Modified single-carrier multilevel sinusoidal pulse width modulation for asymmetrical insulated gate bipolar transistor-clamped grid-connected inverter. IET Power Electronics, 8(8), 1531-1541.

35. Kavali, Janardhan, and Arvind Mittal. "Analysis of various control schemes for minimal Total Harmonic Distortion in cascaded H-bridge multilevel inverter."Journal of Electrical Systems and Information Technology 3.3 (2016): 428-441.

36. Khomfoi, S., Praisuwanna, N., \& Tolbert, L. M. (2010, September). A hybrid cascaded multilevel inverter application for renewable energy resources including a reconfiguration technique. In 2010 IEEE Energy Conversion Congress and Exposition (pp. 3998-4005). IEEE. 
37. Fei, Wanmin, Xiaoli Du, and Bin Wu. "A generalized half-wave symmetry SHE-PWM formulation for multilevel voltage inverters." IEEE Transactions on Industrial Electronics 57.9 (2009): 3030-3038.

38. Routray, A., Patel, V., Mahanty, R., \& Singh, R. K. (2016, December). A novel GA optimized SHE PWM hybrid cascaded H-bridge multilevel inverter with Capacitor Voltage Averaging for motor drive applications. In 2016 IEEE International Conference on Power Electronics, Drives and Energy Systems (PEDES) (pp. 1-5). IEEE.

39. Khesbak, MOHAMMED SMA, IBRAHEEM M. Khaleel, and RIYADH M. Ali. "Enhanced Ac-To-Ac Frequency Changer Based on Multi-Phase Smart Comparative Commutation." Internationa L Journal of Scientific \& Engineering Research, 6, 3144 (2015).

40. Nagaraj, M. S., and P. S. Venkataramu. "Experimental methodology of reduction of harmonics in Power systems to increase power quality using crystal filter." (2014).

41. Patil, I. M., Nagaraj, M. S., \& Venkataramu, P. S. (2016). Simulation of a 3- $\varphi$, 4-Level Inverter with a Discrete 3$\varphi$ PWM Generator for the Suppression of the Harmonics. Simulation, 3(3).

42. Papriwal, A. N. K. I. T. A., and A. M. I. T. A. Mahor. "Review of mitigation of harmonics in multilevel inverters using PSO." International Journal of Electrical and Electronics 2.4 (2012): 65-72.

43. Rodríguez, J., Morán, L., Correa, P., \& Silva, C. (2002). A vector control technique for medium-voltage multilevel inverters. IEEE Transactions on Industrial Electronics, 49(4), 882-888.

44. Tolbert, L. M., \& Habetler, T. G. (1999). Novel multilevel inverter carrier-based PWM method. IEEE Transactions on industry applications, 35(5), 1098-1107.

45. Sun, K. W., Summers, T. J., \& Coates, C. E. (2017, December). Evaluation of peak-to-peak current ripple of phase shifted carrier PWM multilevel cascaded H-bridge converters. In 2017 IEEE Southern Power Electronics Conference (SPEC) (pp. 1-6). IEEE.

46. Amankwah, E. K., Clare, J. C., Wheeler, P. W., \& Watson, A. J. (2012, February). Multi carrier PWM of the modular multilevel VSC for medium voltage applications. In 2012 Twenty-Seventh Annual IEEE Applied Power Electronics Conference and Exposition (APEC) (pp. 2398-2406). IEEE.

47. Sreenivasarao, D., Agarwal, P., \& Das, B. (2013). Performance evaluation of carrier rotation strategy in levelshifted pulse-width modulation technique. IET Power Electronics, 7(3), 667-680.

48. KASSI, KIRTI, and ARVIND MITTAL. "MODIFIED SINGLE PHASE H-BRIDGE MULTI-LEVEL INVERTER TOPOLOGY WITH SPWM TECHNIQUE FOR SOLAR-PV APPLICATION." International Journal of Electrical and Electronics Engineering (IJEEE) 3. 3, May 2014, 59-68

49. Devi, V. K., \& Srivani, S. G. (2017, February). Modified phase shifted PWM for cascaded H bridge multilevel inverter. In 2017 Third International Conference on Advances in Electrical, Electronics, Information, Communication and Bio-Informatics (AEEICB) (pp. 89-94). IEEE.

50. Patel, D., Saravanakumar, R., Ray, K. K., \& Ramesh, R. (2011, January). A review of various carrier based PWM methods for multilevel inverter. In India International Conference on Power Electronics 2010 (IICPE2010) (pp. 1-6). IEEE. 
51. McGrath, B. P., \& Holmes, D. G. (2002). An analytical technique for the determination of spectral components of multilevel carrier-based PWM methods. IEEE Transactions on industrial electronics, 49(4), 847-857.

52. JAIN, PRAMOD, DS AJNAR, and PANKAJ NAIK. "A CMOS TRANSCONDUCTOR WITH ENHANCED LINEARITY AND TUNABILITY IN $0.18 \mu \mathrm{m}$ TECHNOLOGY." International Journal of Electronics and Communication Engineering (IJECE) 2. 4, Sep 2013, 175-182

53. Palanivel, P., \& Dash, S. S. (2011). Analysis of THD and output voltage performance for cascaded multilevel inverter using carrier pulse width modulation techniques. IET Power Electronics, 4(8), 951-958.

54. Holmes, D. G., \& McGrath, B. P. (2001). Opportunities for harmonic cancellation with carrier-based PWM for a two-level and multilevel cascaded inverters. IEEE Transactions on industry applications, 37(2), 574-582.

55. SAMEERA, K., A. SRINIVAS, and MV RAMANA RAO. "IMPROVED POWER FACTOR AND REDUCTION OF HARMONICS BY USING DUAL BOOST CONVERTER FOR PMBLDC MOTOR DRIVE." International Journal of Electrical and Electronics Engineering Research (IJEEER). 4. 5, Oct 2014, 43 - 52

56. Susheela, N., \& Kumar, P. S. (2017). Performance Evaluation of Carrier Based PWM Techniques for Hybrid Multilevel Inverters with Reduced Number of Components. Energy Procedia, 117, 635-642.

57. Rajan, M. S., \& Seyezhai, R. (2013). Comparative study of multicarrier pwm techniques for a modular multilevel inverter. International Journal of Engineering and Technology (IJET), 5(6), 4850-4865.

58. Suresh, Y., \& Panda, A. K. (2013). Investigation on hybrid cascaded multilevel inverter with reduced dc sources. Renewable and Sustainable Energy Reviews, 26, 49-59.

59. Latran, M. B., \& Teke, A. (2015). Investigation of multilevel multifunctional grid connected inverter topologies and control strategies used in photovoltaic systems. Renewable and Sustainable Energy Reviews, 42, $361-376$.

60. Hothongkham, P., \& Kinnares, V. (2007, November). Investigation into harmonic losses in a PWM multilevel cascaded H-bridge inverter fed induction motor. In 2007 7th International Conference on Power Electronics and Drive Systems (pp. 1043-1048). IEEE.

61. Rathore, S., Kirar, M. K., \& Bhardwaj, S. K. (2015). Simulation of cascaded H-bridge multilevel inverter using PD, POD, APOD techniques. Electrical \& Computer Engineering: An International Journal (ECIJ), 4(3), $27-41$.

62. Mohan, D., \& Kurub, S. B. (2012). A comparative analysis of multi carrier SPWM control strategies using fifteen level cascaded H-bridge multilevel inverter. International Journal of Computer Applications, 41(21).

63. Thakre, K., \& Mohanty, K. B. (2015, May). Comparative analysis of THD for symmetrical and asymmetrical 17 level cascaded H-bridge inverter using carrier based PWM techniques. In 2015 International Conference on Industrial Instrumentation and Control (ICIC) (pp. 306-310). IEEE.

64. Dahidah, M. S., \& Agelidis, V. G. (2008). Single-carrier sinusoidal PWM-equivalent selective harmonic elimination for a five-level voltage source converter. Electric Power Systems Research, 78(11), 1826-1836.

65. Dahidah, M. S., Konstantinou, G., \& Agelidis, V. G. (2014). A review of multilevel selective harmonic elimination PWM: formulations, solving algorithms, implementation and applications. IEEE Transactions on Power Electronics, 30(8), 4091-4106. 
66. P.Ramesh, C.Sharmeela, C.Bharathiraja, "Nine Level MLI fed Single phase Induction Motor Drive with Compressor Load using Artificial Neural Network”, Journal of Electrical Engineering, vol.17, no.2, 2017, pp.247-254.

\section{AUTHORS PROFILE}

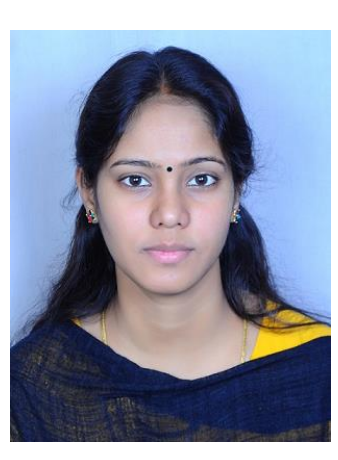

Mrs. Chithra M received her bachelor of engineering degree in Electrical \& Electronics Engineering from MNM Jain Engineering College, Chennai in 2009 and Masters in Power Electronics \& Drives from SVCE, Chennai. She is presently working as Asst Prof in EEE Dept, CMR Institute of Technology, Bengaluru. Achieved Anna University 6th Rank in Master of Engineering in Power Electronics \& Drives 2009-11. She published a paper in the area of power electronics. She has the Indian Science Congress Association (ISCA) and The Indian Society for Technical Education (ISTE) life time membership. Her research area mainly focuses on improvement of power converter performances integrating renewable energy sources by implementing various control techniques. Currently she is doing background studies on soft computing techniques like FL, ANN etc. 
